\title{
The Development of a Smart Health Awareness Message Framework Based on the Use of Social Media: Quantitative Study
}

Elaf Ali Alsisi, BSc, MSc, PhD; Ahmed Al-Ashaab, PhD; Wadhah Ahmed Abualfaraa, BSc, MSc, PhD

Cranfield University, Cranfield, United Kingdom

Corresponding Author:

Elaf Ali Alsisi, BSc, MSc, PhD

Cranfield University

Bedfordshire, MK43 0AL

Cranfield

United Kingdom

Phone: 441234750111 ext 5622

Email: e.alsisi85@gmail.com

\section{Abstract}

Background: Social media has recently provided a remarkable means of delivering health information broadly and in a cost-effective way. Despite its benefits, some difficulties are encountered in attempting to influence the public to change their behavior in response to social media health messages.

Objective: This study aimed to explore the factors that affect individuals' acceptance of using social media as a tool for receiving health awareness messages and adapting such content accordingly by developing a smart health awareness message framework.

Methods: A quantitative method was adapted to validate the hypotheses and proposed framework through the development of a survey based on the technology acceptance model with the extension of other constructs. The survey was distributed on the web to 701 participants from different countries via Qualtrics software; it generated 391 completed questionnaires, and the response rate was $55.8 \%(391 / 701)$.

Results: Of the 391 respondents, 121 (30.9\%) used social media platforms often during the week, and 27 participants (6.9\%) did not use social media. In addition, 24.0\% (94/391) of the respondents used these platforms to seek health information. On the basis of the results, perceived usefulness $(\beta=.37 ; P<.001)$, gain-framed message $(\beta=.04 ; P<.001)$, and loss-framed message $(\beta=.08$; $P<.001)$ were seen to positively and significantly influence people's intention to use social media as a means to spread information about health promotion. The proposed smart health awareness message framework identifies $64.2 \%$ of the variance in intention to use, $55.4 \%$ of the variance of perceived usefulness, and $26.2 \%$ of the variance of perceived ease of use.

Conclusions: This study sheds light on the factors that are associated with people's intention to use and adopt social media in the health promotion domain. The findings reveal that the intention of using social media for health awareness purposes is positively impacted by the perception of usefulness of social media and the design of health messages. Future research might seek to explore other factors that relate to people's behavior. This point of view will assist health organizations in developing their health messages more effectively and to be patient friendly.

(J Med Internet Res 2020;22(7):e16212) doi: 10.2196/16212

\section{KEYWORDS}

social media; health promotion and social media; health awareness; health promotion; eHealth; technology acceptance theory

\section{Introduction}

\section{Background}

The advent of the internet has become a fundamental avenue for gaining health information [1] and for the provision of interventions to enhance healthy behaviors [2]. Rapid and easy access to the internet has driven individuals to go on the web to seek health information [3]. The internet has contributed to the evolution of a new era of communication, known as social media. The phenomenon of social media is defined as a collection of web-based social networking apps that enable individuals or groups of people to communicate and interact with each other, share information, collaborate, and exchange content $[4,5]$. The advancement of the internet, web-based health information, and social media has driven the emergence of electronic health (eHealth). According to the World Health Organization [6], eHealth can be defined as "the use of 
information and communication technologies (ICT)," which involves the development of spreading health information through digital methods $[7,8]$.

One aspect of public health communication, which has received increasing attention, is the media channels through which health messages could be successfully conveyed to a wide range of relevant audiences. Several studies have found that mass media (eg, television, radio, newspaper, leaflets, and posters) have a positive impact on health promotion [9-12]. However, others have marked the ineffectiveness of this impact [13], unlike social media, which has greater potential in health promotion for individuals and health care professionals because of its ability to deliver meaningful health content [14] in different formats such as text, images, and videos [15]. It can be argued, therefore, that social media has largely proved to be an effective and influential instrument in spreading health awareness messages [16] because of its easy access by all socioeconomic strata and its cost effectiveness [3]. Due to the evolution of eHealth and social media tools, health organizations reinforce practitioners in providing health-related information to increase health awareness and obtain better health outcomes $[17,18]$.

Despite the increasing utilization of social media by health organizations in disseminating health awareness, the actual impact of social media interventions demands further research to explore the factors that may affect users' acceptance of this technology and adoption of the content $[15,19]$. These factors include the frame of the message, trust of the content, and the degree of technology acceptance [20-22]. This study is motivated by the need to take into consideration such key factors that lead to effective acceptance of social media as a means to receive, read, and apply health awareness messages.

The paper provides the results of the smart health awareness message framework development and, in turn, ensures spreading health awareness messages effectively on a faster and wider scale through social media. The focus of this paper presents the identification of the factors influencing an individual's intention to use social media as a means to receiving health awareness messages and following its instructions for the well-being of the individual by using the technology acceptance model (TAM) [23], task technology fit (TTF) [24], and prospect theory [25].

The research approach starts with a review of related literature concerning health awareness messages and the use of social media in spreading such messages to a wider community. The second stage involved developing a conceptual framework of the factors influencing an individual's intention to use social media for health promotion. The effectiveness of the proposed framework was evaluated based on the hypotheses developed in this study. To validate these hypotheses, public opinion was analyzed based on a web-based survey using the Qualtrics software with 391 participants.

Such a random sample size would be a good representative because it reflects the characteristics of the population from which it has been drawn (ie, from a wide range of countries) and different opinions that were relatively close to each other.

The remainder of this paper is structured as follows. The first section includes an introduction that presents the research motivation, research approach, and the aim of this paper. The second section presents a review of the related literature. The third section presents the conceptual framework along with the proposed hypotheses. In the fourth section, methods of data collection and measurement development are presented. The section following the fourth section presents some public perspectives of the smart health awareness message framework through data analysis, including testing hypotheses. Finally, the authors conclude with a discussion of the research limitations and future work.

\section{Literature Review}

Public health communication has emerged as a modern strategy to change public behavior by raising awareness of risk diseases. Public health communication refers to "the scientific development, strategic dissemination, and critical evaluation of relevant, accurate, accessible, and understandable health information communicated to and from intended audiences to advance the health of the public" [26]. Therefore, health promotion encompasses the development of approaches that supply health knowledge to individuals, motivating them to adopt the healthy behaviors and change their current ones [27]. Traditionally, mass media has been used as a tool for public health promotion, which has involved a variety of forms including television, newspapers, radio, booklets, billboards, leaflets, and posters $[9,12,28]$. Each format varies according to the level of effectiveness and drawbacks. For example, numerous studies have explored the efficacy of using television campaigns to promote smoking cessation [29,30]. However, exposure to such campaigns has been found to be expensive in comparison with radio broadcasts [12,30].

Although several studies have highlighted the effectiveness of promoting health awareness via leaflets and posters [31-33], the reality is that they are still an expensive media to be published. This is due to the long process and expense of publishing paper-based media and also the factors such as time and labor consumption, limited information being given to the audience [34], poor health content [35], and overlapping information [36]. These reservations also include editing the health content, graphical design, printing, and distributing. Updating any of these printed media requires a further long loop of modification.

Social media has a great potential in public health communication, as it provides patients and the public with the best opportunity by delivering meaningful health content. Ba and Wang [14] found that online social groups have an essential role to play in an individual's routine in terms of encouraging them to adopt a healthy lifestyle through observing their daily diet. Previous research has focused on customized digital health interventions that help individuals to control chronic disease and make proper decisions accordingly [37]. Roland et al [38] developed an online community represented by \#FOAMed on Twitter for the purpose of sharing medical knowledge. Similarly, Diddi and Lundy [39] indicated the usage of Twitter to spread breast cancer awareness by 4 different health organizations, presenting different factors of the health belief model in the content of the message. A previous study has supported diabetic 
people by offering a forum for sharing personal experience and providing feedback on performance by physicians [40].

So far, few research studies have examined the influential factors that affect people's intention to use social media in the health promotion context $[15,20]$. However, understanding these factors is important for designing health promotion messages that incorporate content strategy and simplicity [41]. To fill this research gap, a conceptual smart health awareness message framework was developed based on the TAM, TTF, and prospect theory, as presented in the following section.

The TAM assumes that the extent to which the technology is accepted and used by an individual is predicted by 2 main constructs (factors): perceived usefulness and perceived ease of use [23]. TTF focuses mainly on the features that the technology offers, and thus, it believes that technology must match the task it supports to have performance impact [24]. TTF has 4 key constructs (elements), one of which is technology characteristics. Prospect theory postulates that health communication messages can be designed to shed light on the benefits (gain) or the consequences (loss) of performing a specific behavior [25].

\section{Smart Health Awareness Message Framework and Hypothesis Development}

The smart health awareness message framework includes different elements, which are called constructs, and each construct represents the key factor of a different adapted theory. Thus, this study investigates the impact of such constructs that influence an individual's acceptance of using social media as a tool for receiving health awareness messages and consequently following its instructions for the individual's well-being. The authors adapted the key constructs of 3 theoretical foundations: (1) TAM, (2) TTF, and (3) prospect theory. The TAM serves as a concrete base to develop the conceptual framework. The TTF offers a key element of social media characteristics, whereas the prospect theory provides a theoretical framework for designing such messages. The proposed framework, therefore, will help in designing health messages that will be spread via social media apps.

Figure 1 illustrates smart health awareness message framework, where the authors proposed different hypotheses that provide a statement based on the feature extracted from the intended theory to represent a specific state of an individual's beliefs. This is to be used in a survey to obtain public perspectives on the use of social media technology in receiving health messages. First, they hypothesized that intention to use is influenced by perceived ease of use, perceived usefulness, perceived trust, gain-framed message, and loss-framed message (hypotheses H1, H3, H6, H9, and H10). Second, the authors hypothesized that perceived usefulness is impacted by perceived ease of use, customization, perceived trust, and technology characteristics (H2, H5, H7, and H8). Finally, it was hypothesized that perceived ease of use is influenced by customization $(\mathrm{H} 4)$. Each defined hypothesis supports the relationships among the constructs of the framework. The following subsections present in detail the constructs of smart health awareness message framework.

Figure 1. Smart Health Awareness Message Framework.

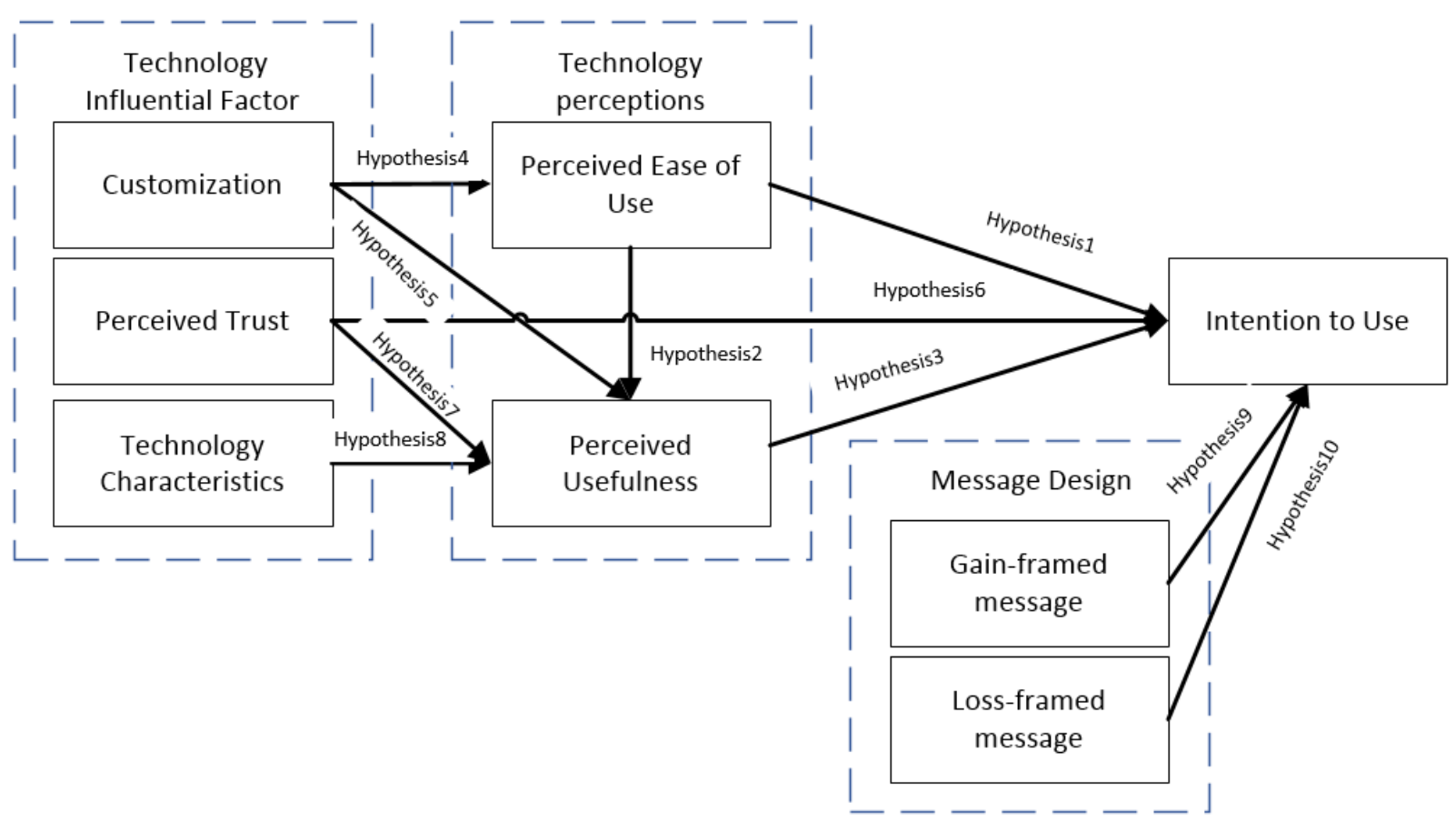

\section{Technology Perceptions}

Technology perceptions include the key elements of the TAM, namely, perceived ease of use and perceived usefulness.
Perceived ease of use, as proposed by Davis [23], alludes to the extent to which the user of the technology will think that the use of a certain tool will be easy or free of effort. As social media supports easy access, easy engagement with its interactions (ie, reply, like, retweet, and repost) [42,43], and 
easy navigation, people's intention will be enhanced to receive and apply health messages accordingly [44]. Exposure to such interactions is generally dynamic, resulting in encouraging health care professionals to create online communities where medical knowledge can be easily shared and freely accessed [38].

A positive association was supported between perceived ease of use and usefulness of technology usage that involved different contexts [45-47]. Therefore, H1 states that perceived ease of use of social media positively influences people's intention to receive and follow health awareness messages. $\mathrm{H} 2$ states that perceived ease of use positively influences perceived usefulness of social media to receive and follow health awareness messages.

Perceived usefulness is widely defined as "the degree to which an individual believes that using a particular system would enhance his/her job performance" [23]. In this study, perceived usefulness refers to the degree to which an individual considers that the benefits of social media will enhance his or her intention to receive and then follow health awareness messages. Some individuals may perceive social media as a personal digital assistant with the purpose of improving medical usage [48].

The link between the usefulness of social media and the intention to adopt such technology as a means to acquire and share health information has been explored by a number of studies [47,49]. Moreover, Deng et al [50] investigated the association between perceived usefulness and the individual's intention to adapt to mobile health. Therefore, H3 states that perceived usefulness of using social media will positively influence people's intention to receive and follow health awareness messages.

\section{Technology-Influencing Factors}

This section includes 3 technology factors, customization, perceived trust, and technology characteristics, which influence the overall perceptions of social media to receive and follow health awareness messages.

Message customization means reaching target people with individualized health messages that work well to engage with the messages effectively [51]. Patrick et al [52] found that people who were exposed to customized text messages with the purpose of promoting dietary behaviors were more likely to achieve weight loss compared with those related to printed materials. Customization in the conceptual framework refers to the empowerment that enables intended systems to understand its users' demographics and interest topics and then tailor their health messages accordingly, for example, the preferable time, the frequency of the messages, the type of disease, and the type of social media platforms. Social media customization provides a number of features that encourage users to prioritize particular accounts to view and act accordingly. On Twitter, Instagram, Facebook, and WhatsApp, by selecting get notifications, a user will automatically be notified every time these accounts post. Thus, such features allow users to easily access and efficiently follow social media posts. By leveraging social media customization efficiently, such technology can be harnessed to be most instrumental and useful in practice.
Customization correlates to perceived usefulness, as evidenced by Ho [53], who found that customized information technology services offer considerable benefits to customers that involve producing right content and format at the proper time for usage motivation purposes. In addition, customization in web-based interfaces has optimized web-based shopping due to its ease of use [54]. Therefore, $\mathrm{H} 4$ states that customization will have a positive impact on perceived ease of use of social media platforms to receive and follow health awareness messages. H5 states that customization will have a positive impact on perceived usefulness of social media platforms to receive and follow health awareness messages.

McAllister [55] defined trust as "the extent to which a person is confident in, and willing to act on the basis of, the words, actions, and decisions of another." He studied the trust between patients and the source of health-related information. Undoubtedly, the trust that individuals place in web-based health knowledge varies with the source of such knowledge. Thus, trust is a significant factor that affects people's adoption of health awareness messages [56,57]. Perceived trust in the framework will evaluate the contextual part of health-related information, and perceived usefulness will evaluate the practical part of social media use for passing health messages.

The association between trust and perceived usefulness has been discussed in several studies, confirming that the more the user perceives the technology to be useful, the greater the likelihood of trusting the content of such technology and therefore their intention to use it [58-60]. Thus, H6 states that perceived trust will positively influence people's intention to use social media to receive and follow health awareness messages. $\mathrm{H} 7$ states that perceived trust will positively impact perceived usefulness of social media to receive and follow health awareness messages.

Technology characteristics constitute a key element of the TTF model identified by Goodhe and Thompson [24], which refers to the extent to which a technology fits when the required tasks are met. The more individuals perceive that the technology suitably fits the intended tasks, the greater the likelihood that they will use that technology [61]. TTF has been used to measure social media appropriateness in many topics, such as sharing information about flood anticipation [62]. A previous study proposed that sharing is a fundamental characteristic that social media provides [63], which refers to the extent to which content can be exchanged among users [64]. For Facebook, Twitter, and Instagram, qualities that correspond to sharing are the message itself and media representation, which involves photographs and videos in terms of photograph quantity and video length [22].

The suitability of TTF depends on the user selection of the technology, which is based on technology characteristics that perfectly correspond to the task's attributes. Hence, this research demonstrates that social media features are capable of boosting the adaptation of this technology in viewing health awareness messages. Earlier studies have investigated the relationship between TTF constructs and perceived usefulness of using SMS for health awareness purposes [65]. Therefore, H8 states that technology characteristics will positively impact perceived usefulness of social media to view health awareness messages. 


\section{Message Design}

This section presents a technique that aids in designing health awareness messages through prospect theory.

In loss- and gain-framed message design, health messages that aim at a particular behavior in terms of its benefits (gains) or costs (losses) play a significant role in health communication $[57,66]$. Health messages, therefore, might be designed either to emphasize the benefits of complying with the message content or the consequences of failure to comply with it $[67,68]$. For instance, a gain-framed message targeting increasing water intake could be drinking a lot of water daily can help you lose weight. In contrast, a loss-framed message could be not drinking enough water causes you to gain weight [69]. According to the prospect theory, the associated persuasion of gain- and loss-framed appeals is linked to the level of risk involved in the relevant actions [25]. The more individuals believe that they are at risk, the more motivated they are to the loss-framed message [57]. Therefore, the effectiveness of gain- and loss-framed messages varies depending on the goal of the message, either preventing or detecting health problems $[66,70]$. Therefore, positive messages are manifested to be more powerful in disease prevention messages [68], such as skin cancer prevention [66], whereas loss-framed messages are more likely to be useful in disease detection [71]. A number of studies have examined the effectiveness of negative messages in designing persuasive health messages. Meyerowitz and Chaiken [71] investigated the issue of women's breast self-assessment, indicating that female students were more encouraged to perform the assessment through passive messages rather than positive ones. Levin et al [72] developed a framing effect-based typology to check the influence of negative- and positive-framed information on decision makers. They concluded that passive goal framing was more convincing and influential than positive ones.

Message frame is believed to have a significant relationship with an individual's intention to adapt to technological invention [73]. Hence, H9 states that the positive effect of gain-framed messages on consumers 'intention to use social media for health awareness purposes would be stronger. On the other hand, hypothesis 10 states that the positive effect of loss-framed messages would be stronger.

\section{Methods}

\section{Data Collection}

The authors developed the questionnaire items based on an understanding of the literature, as presented in Multimedia Appendix 1. Before conducting the survey, it was validated by 5 experts in different industrial and research fields, including community medicine consultants, family medicine consultants, oncologists, and public health specialists based in Saudi Arabia, the United Kingdom, and the United Arab Emirates. Including qualified experts' opinions will assure that items are clarified, accurate, and free of confusion. The survey was distributed on the web through Qualtrics over a 2-month period in 2019, and it produced 701 responses from different countries, with 391 completed surveys.

\section{Development of Questionnaire Items}

The questionnaire included 3 parts: the first part presented the survey's introduction and consent form, the second part focused on the participant's demographics, as shown in Table 1, and the third part included 27 items. Each item is a statement that has been adapted from the literature to measure the opinion of the end user regarding the 7 identified constructs of the conceptual framework. List of items are presented in Multimedia Appendix 1 ; both items and scales were adapted from previous studies with some modifications to fit the research context. Perceived ease of use and intention to use social media items were adapted from Hong et al [74]. The items of perceived usefulness on the intention to use social media were borrowed from El-Wajeeh et al [75]. Items on customization were adapted from Bandyopadhyay et al [65]. The items on the perceived trust construct were adapted from El-Wajeeh et al [75], and items on technology characteristics were derived from Bandyopadhyay et al [65] and Zaini et al [76]. All questionnaire items were rated using a 5-point Likert scale, ranging from strongly disagree (1) to strongly agree (5), in which participants were required to choose the most suitable answer. 
Table 1. Respondent demographics $(\mathrm{N}=391)$.

\begin{tabular}{|c|c|}
\hline Measure & Values, $\mathrm{n}(\%)$ \\
\hline \multicolumn{2}{|l|}{ Gender } \\
\hline Male & $154(39.4)$ \\
\hline Female & $237\left(60.6^{\mathrm{a}}\right)$ \\
\hline \multicolumn{2}{|l|}{ Age (years) } \\
\hline $20-29$ & $91(23.3)$ \\
\hline $30-39$ & $142\left(36.3^{\mathrm{a}}\right)$ \\
\hline $40-49$ & $64(16.4)$ \\
\hline $50-59$ & $52(13.3)$ \\
\hline$\geq 60$ & $42(10.7)$ \\
\hline \multicolumn{2}{|l|}{ Level of education } \\
\hline Secondary school & $9(2.3)$ \\
\hline Bachelor's degree & $125(32.0)$ \\
\hline Master's degree or above & $227\left(58.1^{\mathrm{a}}\right)$ \\
\hline Others & $30(7.7)$ \\
\hline \multicolumn{2}{|l|}{ Job } \\
\hline Governmental employee & $184\left(47.1^{\mathrm{a}}\right)$ \\
\hline Private employee & $85(21.7)$ \\
\hline Self-employed & $21(5.4)$ \\
\hline I do not work & $101(25.8)$ \\
\hline \multicolumn{2}{|c|}{ Frequency of using social media during the week } \\
\hline Always & 74 (18.9) \\
\hline Very often & 75 (19.2) \\
\hline Often & $121\left(31.0^{\mathrm{a}}\right)$ \\
\hline Hardly often & $94(24.0)$ \\
\hline Never & $27(6.9)$ \\
\hline \multicolumn{2}{|c|}{ Frequency of using social media for seeking health information (years) } \\
\hline$<2$ & $121\left(31.0^{\mathrm{a}}\right)$ \\
\hline 2 to $<4$ & $84(21.5)$ \\
\hline $4-6$ & $94(24.0)$ \\
\hline$>6$ & $92(23.5)$ \\
\hline
\end{tabular}

${ }^{\mathrm{a}}$ Indicates the highest percentage.

\section{Respondent Profile and Descriptive Statistics}

The respondents' demographics are illustrated in Table 1. Of the 391 participants, 121 used social media platforms often during the week, with a percentage of $30.9 \%$ (Table 1). In total, $18.9 \%$ (74/391) and $19.2 \%$ (75/391) of the participants used them always and very often during the week, respectively (Table 1). Conversely, 6.9\% (27/391) of the participants never used social media (Table 1). In addition, 24.0\% (94/391) of the respondents utilized these platforms to seek health information (Table 1). This is due to several reasons, including easy and free access to social media, with no physical existence requirement as with health care centers, and no storage capacity is needed as with printed media.

\section{Results}

\section{Data Analysis}

Smart health awareness message framework has been proposed to elicit the opinion of the end user about different constructs, and the results of the survey require a range of statistical methods. First, SPSS (version 25; IBM Corp) was used to acquire respondents' descriptive statistics. Then, data were analyzed using the IBM SPSS Analysis of a Moment Structures 
(AMOS) version 25, which requires 2 stages of assessment: measurement model assessment and structural equation modeling (SEM) assessment. The measurement model was assessed to confirm that the survey items reflected the corresponding constructs of the conceptual framework [77]. SEM was used to test hypothesized relationships among the constructs after conducting confirmatory factor analysis (CFA). The following subsections present the results of exploratory factor analysis (EFA), which includes a measurement model followed by SEM.

\section{Measurement Model}

In the first stage, an EFA was conducted to determine the correlation among observed variables or items being tested. A correlation matrix presented in Multimedia Appendix 2 shows the internal correlations between variables, which are higher than \pm 0.3 , and not exceeding the cut-off threshold, \pm 0.8 , refers to the absence of multicollinearity [77]. Then, EFA was conducted and provided a factor structure of 27 items (Multimedia Appendix 1). These variables are grouped into 7 factors: perceived ease of use, perceived usefulness, customization, perceived trust, technology characteristics, gainand loss-framed message, and intention to use. The factor analysis results are illustrated in Table 2 using maximum likelihood with a promax rotation of data. This analysis shows a clean factor loading pattern, no major cross loading, where values ranged between 0.3 and 0.8 , cut-off criteria [78].

Another issue to be considered in EFA is the appropriateness of the data set that has been verified using the Kaiser-Meyer-Olkin (KMO) statistics and Bartlett test of sphericity. According to Kaiser [79], the KMO value is recommended to be greater than 0.7 to obtain meaningful and good EFA. To assure the factorability of the correlation matrix among variables, the Bartlett test value should be significant $(P<.01)$ [80]. The KMO yielded data adequacy with a value of 0.80 , and the sphericity test showed a statistically significant $\chi_{190}^{2}=2467.0$ ( $P<.01$; Multimedia Appendix 3). Thus, it is evident that the factorability of the correlation matrix is adequate. Then, construct reliability was measured by Cronbach alpha (CA), composite reliability (CR), and average variance extracted (AVE). CA was .893 for the total items; thus, the value was greater than the recommended .7 [78]. Table 3 presents CA for each construct, ranging between .733 and .826 , leading to fit reliabilities of the data. Convergent validity can be assessed by calculating the average variance extracted and CR where the values should be greater than 0.5 and 0.7 , respectively [81]. The results in Table 3 reveal that the AVE and CR applied such criteria. Although the AVE of technology characteristics is below the recommended value, Fornell and Larcker [82] confirmed that a researcher may conclude that the convergent validity of the construct is adequate, as CR is higher than the acceptable range.

Discriminant validity refers to the extent to which the constructs are varied from each other, which can be assessed using the Fornell-Larcker criterion [82]. In this method, the square root of AVE is compared with the correlation of constructs or variables. The variance between constructs and their items should exceed the variance explained with other constructs [82]. Table 4 illustrates that all diagonal square roots of the AVEs were higher than the off-diagonal values, which present constructs' correlations. Given the adequate reliability and acceptable convergent and discriminant validities, it is concluded that the measurement model is satisfactory. 
Table 2. Promax matrix showing factor analysis results.

\begin{tabular}{|c|c|c|c|c|c|c|c|}
\hline Factor $^{\mathrm{a}, \mathrm{b}}$ & 1 & 2 & 3 & 4 & 5 & 6 & 7 \\
\hline & $P U^{c}$ & $\mathrm{PEU}^{\mathrm{d}}$ & $\mathrm{PT}^{\mathrm{e}}$ & $\mathrm{TECH}^{\mathrm{f}}$ & CUST $^{\mathrm{g}}$ & $\mathrm{INT}^{\mathrm{h}}$ & Message $^{\mathrm{i}}$ \\
\hline PU1 & 0.406 & $N / A^{j}$ & N/A & N/A & N/A & N/A & N/A \\
\hline PU2 & 0.512 & N/A & N/A & N/A & N/A & N/A & N/A \\
\hline PEU1 & N/A & 0.789 & N/A & N/A & N/A & N/A & N/A \\
\hline PEU2 & N/A & 0.738 & N/A & N/A & N/A & N/A & N/A \\
\hline PEU3 & N/A & 0.644 & N/A & N/A & N/A & N/A & N/A \\
\hline PEU4 & N/A & 0.562 & N/A & N/A & N/A & N/A & N/A \\
\hline PT1 & N/A & N/A & 0.596 & N/A & N/A & N/A & N/A \\
\hline PT2 & N/A & N/A & 0.839 & N/A & N/A & N/A & N/A \\
\hline TECH1 & N/A & N/A & N/A & 0.379 & N/A & N/A & N/A \\
\hline TECH2 & N/A & N/A & N/A & 0.791 & N/A & N/A & N/A \\
\hline ТЕCH3 & N/A & N/A & N/A & 0.769 & N/A & N/A & N/A \\
\hline TECH4 & N/A & N/A & N/A & 0.379 & N/A & N/A & N/A \\
\hline TECH5 & N/A & N/A & N/A & 0.720 & N/A & N/A & N/A \\
\hline TECH6 & N/A & N/A & N/A & 0.764 & N/A & N/A & N/A \\
\hline TECH7 & N/A & N/A & N/A & 0.725 & N/A & N/A & N/A \\
\hline CUST1 & N/A & N/A & N/A & N/A & 0.821 & N/A & N/A \\
\hline CUST2 & N/A & N/A & N/A & N/A & 0.845 & N/A & N/A \\
\hline CUST3 & N/A & N/A & N/A & N/A & 0.411 & N/A & N/A \\
\hline CUST4 & N/A & N/A & N/A & N/A & 0.301 & N/A & N/A \\
\hline INT1 & N/A & N/A & N/A & N/A & N/A & 0.752 & N/A \\
\hline INT2 & N/A & N/A & N/A & N/A & N/A & 0.783 & N/A \\
\hline INT3 & N/A & N/A & N/A & N/A & N/A & 0.596 & N/A \\
\hline Message1 & N/A & N/A & N/A & N/A & N/A & N/A & 0.723 \\
\hline Message2 & N/A & N/A & N/A & N/A & N/A & N/A & 0.735 \\
\hline Message3 & N/A & N/A & N/A & N/A & N/A & N/A & 0.583 \\
\hline Message4 & N/A & N/A & N/A & N/A & N/A & N/A & 0.536 \\
\hline Message5 & N/A & N/A & N/A & N/A & N/A & N/A & 0.500 \\
\hline
\end{tabular}

${ }^{\text {a }}$ Rotation converged in 7 iterations.

${ }^{\mathrm{b}}$ Extraction method: maximum likelihood; rotation method: Promax with Kaiser normalization.

${ }^{\mathrm{c}} \mathrm{PU}$ : perceived usefulness.

${ }^{\mathrm{d}}$ PEU: perceived ease of use.

${ }^{\mathrm{e}} \mathrm{PT}$ : perceived trust.

${ }^{\mathrm{f}} \mathrm{TECH}$ : technology characteristics.

gCUST: customization.

${ }^{\mathrm{h}}$ INT: intention to use.

${ }^{\mathrm{i}}$ Message: gain- and loss- framed message.

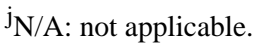


Table 3. Cronbach alpha, composite reliability, and average variance extracted for the constructs.

\begin{tabular}{|c|c|c|c|c|}
\hline Constructs and items & $\mathrm{CA}^{\mathrm{a}}$ & $\mathrm{CR}^{\mathrm{b}}$ & $\mathrm{AVE}^{\mathrm{c}}$ & Factor loading \\
\hline PEU $^{\mathbf{d}}$ & .83 & 0.69 & 0.53 & \\
\hline PEU1 & & & & 0.76 \\
\hline PEU2 & & & & 0.69 \\
\hline PEU3 & & & & 0.80 \\
\hline PEU4 & & & & 0.78 \\
\hline $\mathbf{P U}^{\mathrm{e}}$ & .80 & 0.80 & 0.66 & \\
\hline PU1 & & & & 0.80 \\
\hline PU2 & & & & 0.83 \\
\hline CUST $^{f}$ & .82 & 0.82 & 0.70 & \\
\hline CUST1 & & & & 0.78 \\
\hline CUST2 & & & & 0.89 \\
\hline CUST3 & & & & 0.49 \\
\hline CUST4 & & & & 0.44 \\
\hline $\mathbf{P T}^{\mathrm{g}}$ & .76 & 0.71 & 0.55 & \\
\hline PT1 & & & & 0.78 \\
\hline PT2 & & & & 0.69 \\
\hline TECH $^{h}$ & .75 & 0.71 & 0.38 & \\
\hline TECH1 & & & & 0.60 \\
\hline TECH2 & & & & 0.63 \\
\hline TECH3 & & & & 0.68 \\
\hline TECH4 & & & & 0.55 \\
\hline TECH5 & & & & 0.63 \\
\hline TECH6 & & & & 0.55 \\
\hline TECH7 & & & & 0.43 \\
\hline Message $^{i}$ & .73 & 0.75 & 0.50 & \\
\hline Message1 & & & & 0.81 \\
\hline Message2 & & & & 0.72 \\
\hline Message3 & & & & 0.57 \\
\hline Message4 & & & & 0.53 \\
\hline Message5 & & & & 0.48 \\
\hline INT $^{\mathrm{j}}$ & .76 & 0.77 & 0.62 & \\
\hline INT1 & & & & 0.82 \\
\hline INT2 & & & & 0.76 \\
\hline INT3 & & & & 0.57 \\
\hline
\end{tabular}

${ }^{\mathrm{a} C A}$ : Cronbach alpha.

${ }^{\mathrm{b}} \mathrm{CR}$ : composite reliability.

${ }^{\mathrm{c}}$ AVE: average variance extracted.

${ }^{\mathrm{d}}$ PEU: perceived ease of use.

${ }^{\mathrm{e}} \mathrm{PU}$ : perceived usefulness.

${ }^{\mathrm{f}}$ CUST: customization.

${ }^{\mathrm{g}} \mathrm{PT}$ : perceived trust.

${ }^{\mathrm{h}}$ TECH: technology characteristics. 
${ }^{\mathrm{i}}$ Message: gain-loss framed message.

${ }^{\mathrm{j}}$ INT: intention to use.

Table 4. Discriminant validity.

\begin{tabular}{llllllll}
\hline Factors $^{\mathrm{a}}$ & $\mathrm{PU}^{\mathrm{b}}$ & $\mathrm{PEU}^{\mathrm{c}}$ & $\mathrm{PT}^{\mathrm{d}}$ & TECH $^{\mathrm{e}}$ & CUST $^{\mathrm{f}}$ & & INT $^{\mathrm{g}}$ \\
\hline PU & 0.81 & $\mathrm{~N} / \mathrm{A}^{\mathrm{i}}$ & N/A & N/A & N/A & N/A & N/A \\
PEU & $0.72^{\mathrm{j}}$ & 0.73 & N/A & N/A & N/A & N/A & N/A \\
PT & $0.50^{\mathrm{j}}$ & $0.46^{\mathrm{j}}$ & 0.74 & N/A & N/A & N/A & N/A \\
TECH & $0.57^{\mathrm{j}}$ & $0.66^{\mathrm{j}}$ & $0.59^{\mathrm{j}}$ & 0.62 & N/A & N/A & N/A \\
CUST & $0.29^{\mathrm{j}}$ & $0.27^{\mathrm{j}}$ & $0.36^{\mathrm{j}}$ & $0.32^{\mathrm{j}}$ & 0.84 & N/A & N/A \\
INT & $0.74^{\mathrm{j}}$ & $0.50^{\mathrm{j}}$ & $0.41^{\mathrm{j}}$ & $0.58^{\mathrm{j}}$ & $0.27^{\mathrm{j}}$ & 0.79 & N/A \\
Message & -0.09 & -0.11 & -0.03 & -0.07 & -0.001 & 0.02 & 0.71 \\
\hline
\end{tabular}

${ }^{\mathrm{a}}$ Off-diagonal elements are correlations, and diagonal elements are square roots of the average variance extracted.

${ }^{\mathrm{b}} \mathrm{PU}$ : perceived usefulness.

${ }^{\mathrm{c}}$ PEU: perceived ease of use.

${ }^{\mathrm{d}} \mathrm{PT}$ : perceived trust.

'TECH: technology characteristics.

${ }^{\mathrm{f}}$ CUST: customization.

${ }^{\mathrm{g}}$ INT: intention to use.

${ }^{\mathrm{h}}$ Message: gain-loss framed message.

${ }^{\mathrm{i}} \mathrm{N} / \mathrm{A}$ : not applicable.

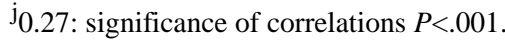

\section{Structural Equation Modeling}

In the second stage, CFA was conducted before testing the hypothesized relationships among the constructs in smart health awareness message framework using SEM [83]. To proceed with CFA, standardized loadings for each item were obtained, in which these values should be at least 0.5 or ideally 0.7 or higher [78]. As shown in Table 5, of the 27 items, CUST3, CUST4, TECH7, and Message5 are attributed to deletion from the research model because of their lower loadings, whereas others are well related to their associated constructs. Given the significant standardized residual covariances, which means the largest values (in absolute value) for items PEU3, PEU4, TECH5, TECH6, Message4, and INT3, they require removal as they affect the goodness fit of the model [84] (Multimedia Appendix 4). The analysis illustrated in Multimedia Appendix 5 confirmed that the linear regression model is adequately fit, with $\chi_{104}^{2}$ value of 299.0 and $P<.001$.

In the second step of the CFA, model fit indexes were measured: $\chi^{2}$ divided by $d f$, root mean square error of approximation (RMSEA), normed fit index (NFI), incremental fit index (IFI), comparative fit index (CFI), and Tucker-Lewis Index (TLI) [83]. The CFA results showed an acceptable fit model $\left(\chi_{97}^{2}=145.8 ; \quad \chi^{2}\right.$ divided by $d f=1.503 ; \quad$ RMSEA $=0.036$; $\mathrm{NFI}=0.937$; IFI=0.978; CFI=0.978; TLI=0.969; Multimedia Appendix 6). The results also confirm that the linear and covariance fit models meet the standards, thus emphasizing the acceptance of model fit (Multimedia Appendices 7 and 8, respectively).

The next step is measuring the path coefficient, coefficient of determination, and $t$ value using SEM. A path coefficient or path analysis indicates the relationships among the constructs. The coefficient of determination (R2) is a measure of the percentage of the total variation of the dependent variable that is explained or predicted by the independent variable(s) or predictor(s) [78]. The larger the value of the coefficient of determination, the greater the prediction of the dependent variable. Table 5 illustrates the path analysis and hypotheses testing. The results show that the coefficient of determination (R2) is 0.642 for the intention to use construct. This means that the 4 constructs (perceived ease of use, perceived usefulness, perceived trust, gain-framed message, and loss-framed message) moderately explain $64.2 \%$ of the variance in intention to use social media. Perceived ease of use, together with customization, perceived trust, and technology characteristics, explain $55.4 \%$ of the variance in perceived usefulness. Finally, customization explains $26.2 \%$ of the variance in perceived ease of use. 
Table 5. Summary of testing hypotheses.

\begin{tabular}{|c|c|c|c|c|}
\hline Hypothesis & Hypothesized path & Beta $^{a}$ & $P$ value & Result \\
\hline H1 & PEU $^{\mathrm{b}}-\mathrm{INT}^{\mathrm{c}}$ & .05 & .43 & Not supported \\
\hline $\mathrm{H} 2$ & PEU-PU ${ }^{\mathrm{d}}$ & .37 & $<.001$ & Supported \\
\hline H3 & PU-INT & .43 & $<.001$ & Supported \\
\hline $\mathrm{H} 4$ & CUST $^{\mathrm{e}}$-PEU & .12 & .12 & Not supported \\
\hline H5 & CUST-PU & .16 & .05 & Supported \\
\hline H6 & $\mathrm{PT}^{\mathrm{f}}$-INT & .11 & .08 & Not supported \\
\hline H7 & PT-PU & .07 & $<.001$ & Supported \\
\hline H8 & $\mathrm{TECH}^{\mathrm{g}}-\mathrm{PU}$ & .12 & $<.001$ & Supported \\
\hline H9 & Gain-framed message-INT & .04 & $<.001$ & Supported \\
\hline $\mathrm{H} 10$ & Loss-framed message-INT & .08 & $<.001$ & Supported \\
\hline
\end{tabular}

${ }^{\mathrm{a}}$ Beta is standardized.

${ }^{b}$ PEU: perceived ease of use.

${ }^{\mathrm{c}}$ INT: intention to use.

${ }^{\mathrm{d}} \mathrm{PU}$ : perceived usefulness.

${ }^{\mathrm{e}}$ CUST: customization.

${ }^{\mathrm{f}} \mathrm{PT}$ : perceived trust.

${ }^{\mathrm{g}} \mathrm{TECH}$ : technology characteristics.

Path analysis results also reveal that perceived ease of usefulness has little effect on intention to use $(\beta=.05 ; P=.43)$, unlike the significant effect on perceived usefulness $(\beta=.37 ; P<.001)$. Thus, $\mathrm{H} 1$ is not supported, whereas H2 is supported. The impact of perceived usefulness on intention to use is significant $(\beta=.43$; $P<.001$ ), supporting H3. However, the results indicate that customization has no significant impact on perceived ease of use $(\beta=.12 ; P=.12)$, whereas it has a significant impact on perceived usefulness $(\beta=.16 ; P=.05)$. Hence, $\mathrm{H} 4$ is not supported, and H5 is supported. The results also indicate that there is no significant impact between perceived trust and intention to use $(\beta=.11 ; P=.07)$. In contrast, perceived trust significantly impacts perceived usefulness $(\beta=.07 ; P<.001)$. Therefore, H6 is not supported, whereas H7 is supported. Technology characteristics are considered to be related and have a significant impact on perceived usefulness $(\beta=.12 ; P<.001)$, lending support to H8. Finally, it was found that gain-framed messages and loss-framed messages are significantly and positively related to intention to use social media $(\beta=.04$; $P<.001)$ and $(\beta=.08 ; P<.001)$, respectively. Thus, H9 and H10 are supported.

\section{Discussion}

\section{Principal Findings}

Nowadays, social media plays a considerable role in an individual's daily routine, as it provides different features that encourage people to adapt it for a range of uses, including health promotion. Therefore, the motivation of this paper was to examine the factors that affect people's intention to use social media as a way of receiving health awareness messages, which, in turn, will help them to maintain their diet and reduce the incidence of diseases. In turn, the challenges that arise from printed media, involving paper and power consumption, storage capacity, and labor intensity, will be reduced. The results in Table 1 show that $69.0 \%$ (270/391) of the public surveyed used social media always, often, or very often, and $31.0 \%$ (121/391) of them hardly or never used social media. This indicates that eHealth that involves using social media to convey health messages has the potential to reach about $70 \%$ of the public. Findings (shown in Figure 2) confirm that perceived usefulness and message design relating to health message frames (positive vs negative) are the leading predictors of people's intention to use social media in the health promotion context. Loss-framed messages have been examined in previous studies $[85,86]$ to be a motivating factor that influences people to engage and comply with health behavior on social media. A recent study has come to an opposing conclusion where people are encouraged to acquire and trust health information on social media when they are exposed to gain-framed messages [87]. Regarding social media usefulness, the results of this study are consistent with those of Lin and Ho [49], indicating that perceived usefulness significantly affects people toward social media adaptation in sharing health information. 
Figure 2. Hypothesized Smart Health Awareness Message Framework. $* P<.05$, ** $P<.01, * * * P<.001$; ns: nonsignificant.

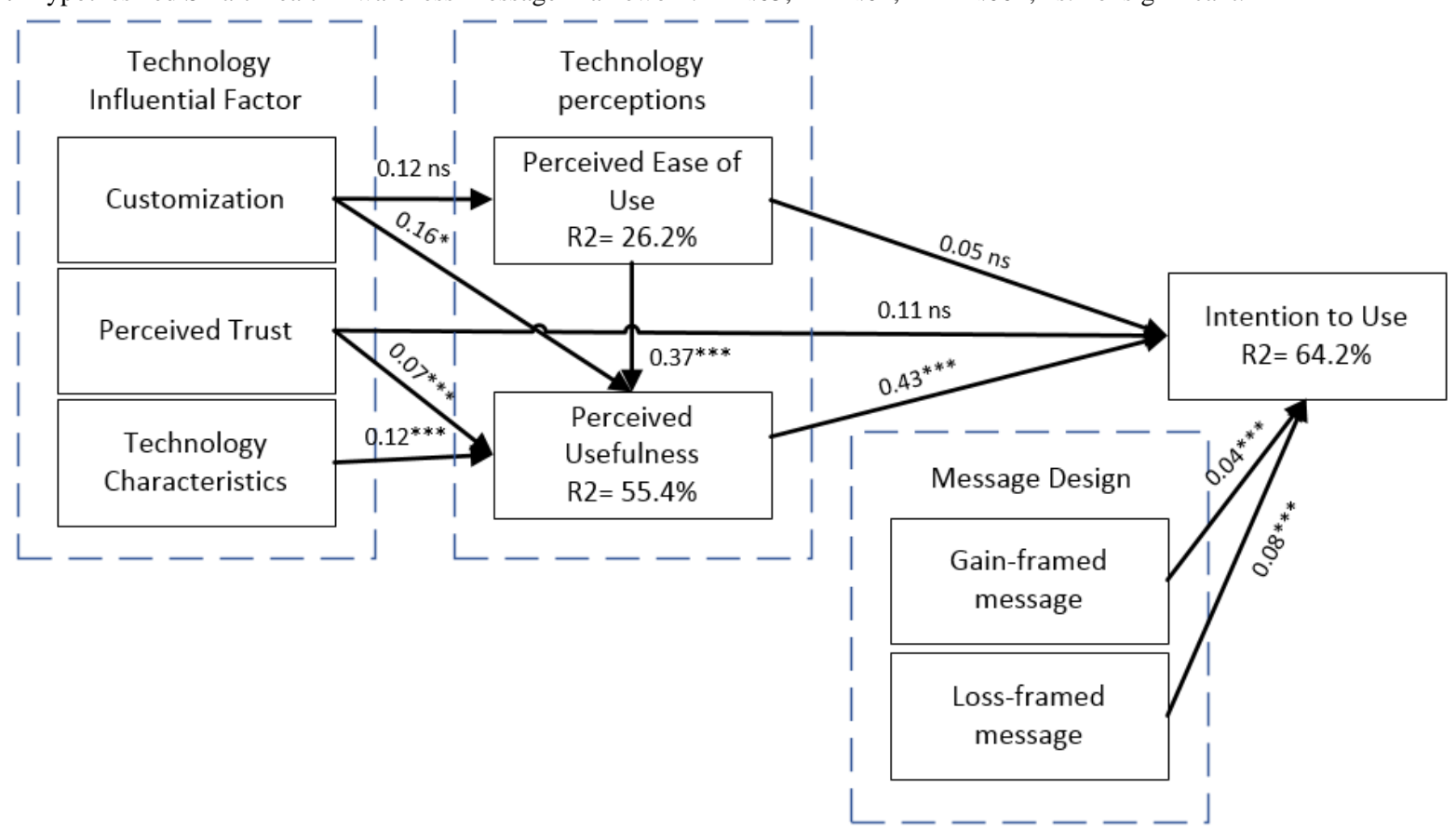

In addition, health message customization encourages the prediction of perceived usefulness, whereas it has no effect on perceived ease of use of social media. Thus, it can be indicated that social media users perceive the acquired benefits from social media when they receive health messages tailored to their preferences [51]. Regarding the relationship between technology characteristics and perceived usefulness $(\beta=.12 ; P<.001)$, it can be concluded that the higher the characteristics offered by social media, the greater the perceptions of the benefits of adopting health messages received via social media. These characteristics involve hyperlinks and hashtags provision, which, in turn, generate higher engagement with messages [88]. Moreover, posting photographs and videos that enhance the message by being more visual encourage individuals to adopt social media for health promotion [15]. The results reveal that the design of health messages plays a significant role in people's intention to use social media. Consequently, the key factors specified are essential for health organizations to promote eHealth by developing and spreading health messages effectively, which, in turn, will enhance people's health.

\section{Conclusions}

The study's results demonstrate the use of social media in health promotion purposes, which will enhance the outcomes of an individual's well-being. This paper aimed to investigate the influential factors that affect people's intention to adopt such technology in health communication campaigns. Undoubtedly, high levels of health message success cannot be achieved without emotions embedded in the content of health messages [89]. The study's findings indicate that health message frames would be efficacious in improving public health communication toward social media adaptation. Furthermore, perceived usefulness has an impact on people's intention to adapt to social media to acquire health awareness information. These results can be explained by the adaptation of the TAM and the prospect theory.
Given the findings of smart health awareness message framework, designing health awareness messages to include loss- or gain-framed content to evoke high emotions might contribute to boosting the effectiveness of health promotion interventions. Hence, this study offers implications for health awareness message developers that guide them to establish materials that are more patient friendly and technologically outstanding by adapting social media as a delivery method. Accordingly, this strategy will encourage individuals to exchange these messages among social media users.

\section{Limitations and Future Work}

This study has several limitations and indicates several directions for future work. First, for the construct of message design, there are few studies associated with the prospect theory that examine the public perspective in terms of their preferences. Thus, the authors developed a number of items, validated by experts, and adapted in this study to ensure the validity of the construct. Future works might examine this construct more broadly to determine the extent to which the public might receive this message in a more positive or negative manner. Second, although the study involved 391 respondents from different countries, in which sample size is convenient for testing the framework, future studies with larger samples are needed to reinforce the generalization of results. In addition, the participants were English speakers, and findings related to a particular language might restrict generalization to others. Thus, future research might duplicate this study with different languages.

Smart health awareness message framework will also be used to define the right content and format of the health awareness messages to be spread via a software system that is integrated with different social media platforms. Furthermore, a computer-based knowledge framework based on the use of social media apps will be developed to spread health awareness messages. Finally, a specific statistical technique will be used 
to validate the impact of the health awareness message on recipients.

\section{Conflicts of Interest}

None declared.

\section{Multimedia Appendix 1}

Items of the study's constructs.

[DOCX File, $17 \mathrm{~KB}-$ Multimedia Appendix 1]

\section{Multimedia Appendix 2}

Items correlation matrix.

[DOCX File, 158 KB-Multimedia Appendix 2]

\section{Multimedia Appendix 3}

Kaiser-Meyer-Olkin and Bartlett test.

[DOCX File, 12 KB-Multimedia Appendix 3]

\section{Multimedia Appendix 4}

Standardized residual covariances for deleted items.

[DOCX File , $31 \mathrm{~KB}$-Multimedia Appendix 4]

\section{Multimedia Appendix 5}

Standardized estimate of linear regression.

[DOCX File, 174 KB-Multimedia Appendix 5]

\section{Multimedia Appendix 6}

Model fit summary.

[DOCX File, 13 KB-Multimedia Appendix 6]

\section{Multimedia Appendix 7}

Covariance fit model.

[DOCX File, 14 KB-Multimedia Appendix 7]

\section{Multimedia Appendix 8}

Standardized regression weights among items.

[DOCX File, 13 KB-Multimedia Appendix 8]

\section{References}

1. Ritterband LM, Borowitz S, Cox DJ, Kovatchev B, Walker LS, Lucas V, et al. Using the internet to provide information prescriptions. Pediatrics 2005 Nov;116(5):e643-e647. [doi: 10.1542/peds.2005-0404] [Medline: 16263978]

2. Webb TL, Joseph J, Yardley L, Michie S. Using the internet to promote health behavior change: a systematic review and meta-analysis of the impact of theoretical basis, use of behavior change techniques, and mode of delivery on efficacy. J Med Internet Res 2010 Feb 17;12(1):e4 [FREE Full text] [doi: 10.2196/jmir.1376] [Medline: 20164043]

3. Syn SY, Kim SU. College students' health information activities on Facebook: investigating the impacts of health topic sensitivity, information sources, and demographics. J Health Commun 2016 Jul;21(7):743-754. [doi: 10.1080/10810730.2016.1157652] [Medline: 27220029]

4. Salem J, Borgmann H, Murphy DG. Integrating social media into urologic health care: what can we learn from other disciplines? Curr Urol Rep 2016 Feb;17(13):13. [doi: 10.1007/s11934-015-0570-2] [Medline: 26757907]

5. Brusilovskiy E, Townley G, Snethen G, Salzer MS. Social media use, community participation and psychological well-being among individuals with serious mental illnesses. Comput Human Behav 2016 Dec;65:232-240. [doi:

10.1016/j.chb.2016.08.036]

6. World Health Organization. National EHealth Strategy Toolkit. Geneva, Switzerland: WHO Publications; 2012. 
7. Albalawi YA, Sixsmith J. Exploring the diffusion of tweets designed to raise the road safety agenda in Saudi Arabia. Glob Health Promot 2017 Dec;24(4):5-13. [doi: 10.1177/1757975915626111] [Medline: 27251329]

8. Thabrew H, Stasiak K, Hetrick SE, Wong S, Huss JH, Merry SN. E-health interventions for anxiety and depression in children and adolescents with long-term physical conditions. Cochrane Database Syst Rev 2018 Aug 15;8:CD012489 [FREE Full text] [doi: 10.1002/14651858.CD012489.pub2] [Medline: 30110718]

9. Noar SM. A 10-year retrospective of research in health mass media campaigns: where do we go from here? J Health Commun 2006;11(1):21-42. [doi: 10.1080/10810730500461059] [Medline: 16546917]

10. Boles M, Adams A, Gredler A, Manhas S. Ability of a mass media campaign to influence knowledge, attitudes, and behaviors about sugary drinks and obesity. Prev Med 2014 Oct;67(Suppl 1):S40-S45 [FREE Full text] [doi: 10.1016/j.ypmed.2014.07.023] [Medline: 25066020]

11. Wakefield MA, Loken B, Hornik RC. Use of mass media campaigns to change health behaviour. Lancet 2010 Oct 9;376(9748):1261-1271 [FREE Full text] [doi: 10.1016/S0140-6736(10)60809-4] [Medline: 20933263]

12. Austin LS, Husted K. Cost-effectiveness of television, radio, and print media programs for public mental health education. Psychiatr Serv 1998 Jun;49(6):808-811. [doi: 10.1176/ps.49.6.808] [Medline: 9634162]

13. Randolph W, Viswanath K. Lessons learned from public health mass media campaigns: marketing health in a crowded media world. Annu Rev Public Health 2004;25(1):419-437. [doi: 10.1146/annurev.publhealth.25.101802.123046] [Medline: 15015928]

14. Ba S, Wang L. Digital health communities: the effect of their motivation mechanisms. Decis Support Syst 2013 Nov;55(4):941-947. [doi: 10.1016/j.dss.2013.01.003]

15. Li Y, Wang X, Lin X, Hajli M. Seeking and sharing health information on social media: a net valence model and cross-cultural comparison. Technol Forecast Soc Chang 2018 Jan;126:28-40. [doi: 10.1016/j.techfore.2016.07.021]

16. Lyson HC, Le GM, Zhang J, Rivadeneira N, Lyles C, Radcliffe K, et al. Social media as a tool to promote health awareness: results from an online cervical cancer prevention study. J Cancer Educ 2019 Aug;34(4):819-822. [doi: 10.1007/s13187-018-1379-8] [Medline: 29948924]

17. Hazzam J, Lahrech A. Health care professionals' social media behavior and the underlying factors of social media adoption and use: quantitative study. J Med Internet Res 2018 Nov 7;20(11):e12035 [FREE Full text] [doi: 10.2196/12035] [Medline: 30404773]

18. Moorhead SA, Hazlett DE, Harrison L, Carroll JK, Irwin A, Hoving C. A new dimension of health care: systematic review of the uses, benefits, and limitations of social media for health communication. J Med Internet Res 2013 Apr 23;15(4):e85 [FREE Full text] [doi: 10.2196/jmir.1933] [Medline: 23615206]

19. Mouakket S. Factors influencing continuance intention to use social network sites: the Facebook case. Comput Human Behav 2015 Dec;53:102-110. [doi: 10.1016/j.chb.2015.06.045]

20. Balatsoukas P, Kennedy CM, Buchan I, Powell J, Ainsworth J. The role of social network technologies in online health promotion: a narrative review of theoretical and empirical factors influencing intervention effectiveness. J Med Internet Res 2015 Jun 11;17(6):e141 [FREE Full text] [doi: 10.2196/jmir.3662] [Medline: 26068087]

21. Welch V, Petkovic J, Pardo JP, Rader T, Tugwell P. Interactive social media interventions to promote health equity: an overview of reviews. Health Promot Chronic Dis Prev Can 2016 Apr;36(4):63-75 [FREE Full text] [doi: 10.24095/hpcdp.36.4.01] [Medline: 27077792]

22. Huo C, Zhang M, Ma F. Factors influencing people's health knowledge adoption in social media: the mediating effect of trust and the moderating effect of health threat. Libr Hi Tech 2018 Mar 19;36(1):129-151. [doi: 10.1108/lht-04-2017-0074]

23. Davis FD. Perceived usefulness, perceived ease of use, and user acceptance of information technology. MIS Q 1989 Sep;13(3):319-313. [doi: 10.2307/249008]

24. Goodhue DL, Thompson RL. A mucoprotein derived from human urine which reacts with influenza, mumps, and Newcastle disease viruses. MIS Q 1995;19(2):71-97. [Medline: 14907962]

25. Tversky A, Kahneman D. The framing of decisions and the psychology of choice. Science 1981 Jan 30;211(4481):453-458. [doi: 10.1126/science.7455683] [Medline: 7455683]

26. Bernhardt JM. Communication at the core of effective public health. Am J Public Health 2004 Dec;94(12):2051-2053. [doi: 10.2105/ajph.94.12.2051] [Medline: 15569948]

27. Frati A, Luzi AM, Colucci A. Communication for health promotion: history and identification of effective methods. Ann Ist Super Sanita 2010;46(4):422-426 [FREE Full text] [doi: 10.4415/ANN 1004 10] [Medline: 21169674]

28. Catalán-Matamoros D. The role of mass media in public health. Am J Public Health Nations Health 1960 Apr;50:515-523. [doi: 10.2105/ajph.50.4.515] [Medline: 13829314]

29. Sims M, Langley T, Lewis S, Richardson S, Szatkowski L, McNeill A, et al. Effectiveness of tobacco control television advertisements with different types of emotional content on tobacco use in England, 2004-2010. Tob Control 2016 Jan;25(1):21-26 [FREE Full text] [doi: 10.1136/tobaccocontrol-2013-051454] [Medline: 25037155]

30. Farrelly MC, Hussin A, Bauer UE. Effectiveness and cost effectiveness of television, radio and print advertisements in promoting the New York smokers' quitline. Tob Control 2007 Dec;16(Suppl 1):i21-i23 [FREE Full text] [doi: 10.1136/tc.2007.019984] [Medline: 18048625] 
31. Macfarlane JT, Holmes WF, Macfarlane RM. Reducing reconsultations for acute lower respiratory tract illness with an information leaflet: a randomized controlled study of patients in primary care. Br J Gen Pract 1997 Nov;47(424):719-722 [FREE Full text] [Medline: 9519518]

32. Steele M, Dow L, Baxter G. Promoting public awareness of the links between lifestyle and cancer: a controlled study of the usability of health information leaflets. Int J Med Inform 2011 Dec;80(12):e214-e229. [doi:

10.1016/j.ijmedinf.2011.08.012] [Medline: 22020199]

33. Jenner EA, Jones F, Fletcher BC, Miller L, Scott GM. Hand hygiene posters: selling the message. J Hosp Infect 2005 Feb;59(2):77-82. [doi: 10.1016/j.jhin.2004.07.002] [Medline: 15702513]

34. Winterbottom A, Conner M, Mooney A, Bekker H. Evaluating the quality of patient leaflets about renal replacement therapy across UK renal units. Nephrol Dial Transplant 2007 Aug;22(8):2291-2296. [doi: 10.1093/ndt/gfm095] [Medline: 17369614]

35. McNulty CA, Nichols T, Boyle PJ, Woodhead M, Davey P. The English antibiotic awareness campaigns: did they change the public's knowledge of and attitudes to antibiotic use? J Antimicrob Chemother 2010 Jul;65(7):1526-1533. [doi: 10.1093/jac/dkq126] [Medline: 20488985]

36. Lee C. The interplay between media use and interpersonal communication in the context of healthy lifestyle behaviors: reinforcing or substituting? Mass Commun Soc 2009 Dec;13(1):48-66 [FREE Full text] [doi: 10.1080/15205430802694869] [Medline: 25598709]

37. Were MC, Kamano JH, Vedanthan R. Leveraging digital health for global chronic diseases. Glob Heart 2016 Dec;11(4):459-462. [doi: 10.1016/j.gheart.2016.10.017] [Medline: 27938842]

38. Roland D, Spurr J, Cabrera D. Preliminary evidence for the emergence of a health care online community of practice: using a netnographic framework for Twitter hashtag analytics. J Med Internet Res 2017 Jul 14;19(7):e252 [FREE Full text] [doi: 10.2196/jmir.7072] [Medline: 28710054]

39. Diddi P, Lundy LK. Organizational twitter use: content analysis of tweets during breast cancer awareness month. J Health Commun 2017 Mar;22(3):243-253. [doi: 10.1080/10810730.2016.1266716] [Medline: 28248621]

40. Greene JA, Choudhry NK, Kilabuk E, Shrank WH. Online social networking by patients with diabetes: a qualitative evaluation of communication with Facebook. J Gen Intern Med 2011 Mar;26(3):287-292 [FREE Full text] [doi: 10.1007/s11606-010-1526-3] [Medline: 20945113]

41. Kreps GL, Neuhauser L. New directions in eHealth communication: opportunities and challenges. Patient Educ Couns 2010 Mar;78(3):329-336. [doi: 10.1016/j.pec.2010.01.013] [Medline: 20202779]

42. Goodyear VA, Armour KM, Wood H. Young people and their engagement with health-related social media: new perspectives. Sport Educ Soc 2019;24(7):673-688 [FREE Full text] [doi: 10.1080/13573322.2017.1423464] [Medline: $\underline{31814804]}$

43. McGowan BS, Wasko M, Vartabedian BS, Miller RS, Freiherr DD, Abdolrasulnia M. Understanding the factors that influence the adoption and meaningful use of social media by physicians to share medical information. J Med Internet Res 2012 Sep 24;14(5):e117 [FREE Full text] [doi: 10.2196/jmir.2138] [Medline: 23006336]

44. Dumas A, Lapointe A, Desroches S. Users, uses, and effects of social media in dietetic practice: scoping review of the quantitative and qualitative evidence. J Med Internet Res 2018 Feb 20;20(2):e55 [FREE Full text] [doi: 10.2196/jmir.9230] [Medline: 29463487]

45. Yu P, Li H, Gagnon M. Health IT acceptance factors in long-term care facilities: a cross-sectional survey. Int J Med Inform 2009 Apr;78(4):219-229. [doi: 10.1016/j.ijmedinf.2008.07.006] [Medline: 18768345]

46. Guo X, Sun Y, Wang N, Peng Z, Yan Z. The dark side of elderly acceptance of preventive mobile health services in China. Electron Mark 2012 Dec 11;23(1):49-61. [doi: 10.1007/s12525-012-0112-4]

47. Ramírez-Correa P, Grandón EE, Ramírez-Santana M, Órdenes LB. Explaining the use of social network sites as seen by older adults: the enjoyment component of a hedonic information system. Int J Environ Res Public Health 2019 May 14;16(10):1673 [FREE Full text] [doi: 10.3390/ijerph16101673] [Medline: 31091670]

48. Yi MY, Jackson JD, Park JS, Probst JC. Understanding information technology acceptance by individual professionals: toward an integrative view. Inf Manag 2006 Apr;43(3):350-363. [doi: 10.1016/j.im.2005.08.006]

49. Lin H, Ho W. Cultural effects on use of online social media for health-related information acquisition and sharing in Taiwan. Int J Hum Comput Interact 2018 Apr 10;34(11):1063-1076. [doi: 10.1080/10447318.2017.1413790]

50. Deng Z, Hong Z, Ren C, Zhang W, Xiang F. What predicts patients' adoption intention toward mhealth services in China: empirical study. JMIR Mhealth Uhealth 2018 Aug 29;6(8):e172 [FREE Full text] [doi: 10.2196/mhealth.9316] [Medline: $\underline{30158101]}$

51. Franklin VL, Waller A, Pagliari C, Greene SA. A randomized controlled trial of Sweet Talk, a text-messaging system to support young people with diabetes. Diabet Med 2006 Dec;23(12):1332-1338. [doi: 10.1111/j.1464-5491.2006.01989.x] [Medline: 17116184$]$

52. Patrick K, Raab F, Adams MA, Dillon L, Zabinski M, Rock CL, et al. A text message-based intervention for weight loss: randomized controlled trial. J Med Internet Res 2009 Jan 13;11(1):e1 [FREE Full text] [doi: 10.2196/jmir.1100] [Medline: 19141433]

53. Ho SY. The effects of location personalization on individuals' intention to use mobile services. Decis Support Syst 2012 Nov;53(4):802-812. [doi: 10.1016/j.dss.2012.05.012] 
54. Kumar RL, Smith MA, Bannerjee S. User interface features influencing overall ease of use and personalization. Inf Manag 2004 Jan;41(3):289-302. [doi: 10.1016/s0378-7206(03)00075-2]

55. McAllister DJ. Affect- and cognition-based trust as foundations for interpersonal cooperation in organizations. Acad Manag J 1995 Feb 1;38(1):24-59. [doi: 10.2307/256727]

56. Ruppel EK. Scanning health information sources: applying and extending the comprehensive model of information seeking. J Health Commun 2016;21(2):208-216. [doi: 10.1080/10810730.2015.1058438] [Medline: 26716985]

57. Macapagal K, Janssen E, Matson M, Finn PR, Heiman JR. The impact of gain- and loss-framed messages on young adults' sexual decision making: an experimental study. Arch Sex Behav 2017 Feb;46(2):385-394 [FREE Full text] [doi: 10.1007/s10508-015-0679-x] [Medline: 26696408]

58. Geven D, Karahanna E, Straub DW. Trust and TAM in online shopping: an integrated model. MIS Q 2003 May;27(1):51-59. [doi: $10.2307 / 30036519]$

59. Wu I, Chen J. An extension of Trust and TAM model with TPB in the initial adoption of on-line tax: an empirical study. Int J Hum Comput Stud 2005 Jun;62(6):784-808. [doi: 10.1016/j.ijhcs.2005.03.003]

60. Chinomona R. The influence of perceived ease of use and perceived usefulness on trust and intention to use mobile social software. African J Phys Heal Educ Recreat Danc 2013;19(2):258-273 [FREE Full text]

61. Lippert SK, Forman H. A supply chain study of technology trust and antecedents to technology internalization consequences. Int Jnl Phys Dist Log Manage 2006 Apr;36(4):271-288. [doi: 10.1108/09600030610672046]

62. Hashim K, Ishak S, Ahmad M. A study on social media application as a tool to share information during flood disaster. J Eng Appl Sci 2015;10(3):959-967 [FREE Full text]

63. Kietzmann JH, Hermkens K, McCarthy IP, Silvestre BS. Social media? Get serious! Understanding the functional building blocks of social media. Bus Horiz 2011 May;54(3):241-251. [doi: 10.1016/j.bushor.2011.01.005]

64. Lu H, Yang Y. Toward an understanding of the behavioral intention to use a social networking site: an extension of task-technology fit to social-technology fit. Comput Human Behav 2014;34:323-332. [doi: 10.1016/j.chb.2013.10.020]

65. Bandyopadhyay T, Meso P, Negash S. Mobile IT in health-the case of short messaging service in an HIV awareness program. Inf Technol Dev 2017 Aug 23;24(2):359-397. [doi: 10.1080/02681102.2017.1363029]

66. Gallagher KM, Updegraff JA. Health message framing effects on attitudes, intentions, and behavior: a meta-analytic review. Ann Behav Med 2012 Feb;43(1):101-116. [doi: 10.1007/s12160-011-9308-7] [Medline: 21993844]

67. Rothman AJ, Salovey P. Shaping perceptions to motivate healthy behavior: the role of message framing. Psychol Bull 1997 Jan;121(1):3-19. [doi: 10.1037/0033-2909.121.1.3] [Medline: 9000890]

68. Latimer AE, Brawley LR, Bassett RL. A systematic review of three approaches for constructing physical activity messages: what messages work and what improvements are needed? Int J Behav Nutr Phys Act 2010 May 11;7:36 [FREE Full text] [doi: 10.1186/1479-5868-7-36] [Medline: 20459779]

69. Shamaskin AM, Mikels JA, Reed AE. Getting the message across: age differences in the positive and negative framing of health care messages. Psychol Aging 2010 Sep;25(3):746-751. [doi: 10.1037/a0018431] [Medline: 20677886]

70. Akl EA, Oxman AD, Herrin J, Vist GE, Terrenato I, Sperati F, et al. Framing of health information messages. Cochrane Database Syst Rev 2011 Dec 7;7(12):CD006777. [doi: 10.1002/14651858.CD006777.pub2] [Medline: 22161408]

71. Meyerowitz BE, Chaiken S. The effect of message framing on breast self-examination attitudes, intentions, and behavior. J Pers Soc Psychol 1987 Mar;52(3):500-510. [doi: 10.1037//0022-3514.52.3.500] [Medline: 3572721]

72. Levin IP, Schneider SL, Gaeth GJ. All frames are not created equal: a typology and critical analysis of framing effects. Organ Behav Hum Decis Process 1998 Nov;76(2):149-188. [doi: 10.1006/obhd.1998.2804] [Medline: 9831520]

73. Vishwanath A. From belief-importance to intention: the impact of framing on technology adoption. Commun Monogr 2009 May 13;76(2):177-206. [doi: 10.1080/03637750902828438]

74. Hong S, Thong J, Moon J, Tam K. Understanding the behavior of mobile data services consumers. Inf Syst Front 2008 Jun 12;10(4):431-445 [FREE Full text] [doi: 10.1007/s10796-008-9096-1]

75. El-Wajeeh M, Galal-Edeen G, Mokhtar H. Technology acceptance model for mobile health systems. J Mob Comput Appl 2014;1(1):21-33 [FREE Full text] [doi: 10.9790/0050-0112133]

76. Zaini M, Shahibi M, Kadir W, Ibrahim Z. Identification of trust factor in digital health information from the internet among clinic attendees. Int J Comput Inf Technol 2013;2(5):880-887 [FREE Full text]

77. Field A. Discovering Statistics Using SPSS. Third Edition. Thousand Oaks, CA: Sage Publications; 2009.

78. Hair J, Black W, Babin BJ, Anderson RE. Multivariate Data Analysis: With Readings. Seventh Edition. England, UK: Pearson; 2014.

79. Kaiser HF. An index of factorial simplicity. Psychometrika 1974 Mar;39(1):31-36. [doi: 10.1007/bf02291575]

80. Tabachnick B, Fidell L. Using multivariate statistics. In: Using Multivariate Statistics. Sixth Edition. England, UK: Pearson; 2013.

81. MacKenzie SB, Podsakoff PM, Podsakoff NP. Construct measurement and validation procedures in MIS and behavioral research: integrating new and existing techniques. MIS Q 2011;35(2):293. [doi: 10.2307/23044045]

82. Fornell C, Larcker DF. Evaluating structural equation models with unobservable variables and measurement error. J Mark Res 2018 Nov 28;18(1):39-50. [doi: 10.1177/002224378101800104] 
83. Anderson JC, Gerbing DW. Structural equation modeling in practice: a review and recommended two-step approach. Psychol Bull 1988 May;103(3):411-423. [doi: 10.1037/0033-2909.103.3.411]

84. Maydeu-Olivares A, Shi D. Effect sizes of model misfit in structural equation models: standardized residual covariances and residual correlations. Methodology 2017 Jun;13(Supplement 1):23-30. [doi: 10.1027/1614-2241/a000129]

85. Gough A, Hunter RF, Ajao O, Jurek A, McKeown G, Hong J, et al. Tweet for behavior change: using social media for the dissemination of public health messages. JMIR Public Health Surveill 2017 Mar 23;3(1):e14 [FREE Full text] [doi: 10.2196/publichealth.6313] [Medline: 28336503]

86. Lee-Won R, Na K, Coduto K. The effects of social media virality metrics, message framing, and perceived susceptibility on cancer screening intention: the mediating role of fear. Telemat Informatics 2017 Dec;34(8):1387-1397. [doi: 10.1016/j.tele.2017.06.002]

87. Borah P, Xiao X. The importance of 'likes': the interplay of message framing, source, and social endorsement on credibility perceptions of health information on Facebook. J Health Commun 2018;23(4):399-411. [doi: 10.1080/10810730.2018.1455770] [Medline: 29601271]

88. Bhattacharya S, Srinivasan P, Polgreen P. Engagement with health agencies on Twitter. PLoS One 2014;9(11):e112235 [FREE Full text] [doi: 10.1371/journal.pone.0112235] [Medline: 25379727]

89. Nabi RL, Walter N, Oshidary N, Endacott CG, Love-Nichols J, Lew ZJ, et al. Can emotions capture the elusive gain-loss framing effect? A meta-analysis. Communic Res 2019 Jul 13;1:1-24. [doi: 10.1177/0093650219861256]

\author{
Abbreviations \\ AVE: average variance extracted \\ CA: Cronbach alpha \\ CFA: confirmatory factor analysis \\ CFI: comparative fit index \\ CR: composite reliability \\ EFA: exploratory factor analysis \\ eHealth: electronic health \\ IFI: incremental fit index \\ KMO: Kaiser-Meyer-Olkin \\ NFI: normed fit index \\ RMSEA: root mean square error of approximation \\ SEM: structural equation modeling \\ TAM: technology acceptance model \\ TLI: Tucker-Lewis Index \\ TTF: task technology fit
}

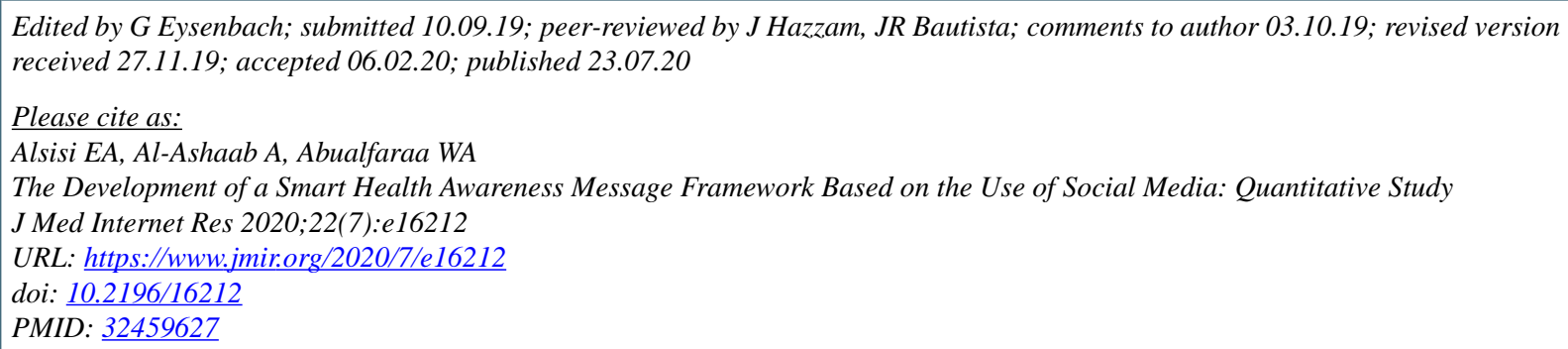

CElaf Ali Alsisi, Ahmed Al-Ashaab, Wadhah Ahmed Abualfaraa. Originally published in the Journal of Medical Internet Research (http://www.jmir.org), 23.07.2020. This is an open-access article distributed under the terms of the Creative Commons Attribution License (https://creativecommons.org/licenses/by/4.0/), which permits unrestricted use, distribution, and reproduction in any medium, provided the original work, first published in the Journal of Medical Internet Research, is properly cited. The complete bibliographic information, a link to the original publication on http://www.jmir.org/, as well as this copyright and license information must be included. 